\title{
Study on Construction Science \& Technology Development using AHP-SWOT Method
}

\author{
Xiaofan Jiang ${ }^{1, a}$, Qiankun Wang ${ }^{2, b}$ and Weiwei Zuo ${ }^{3, c}$ \\ ${ }^{1}$ School of civil engineering and architecture Wuhan University of Technology, China \\ awangqk@ whut.edu.cn, bxsjxf@126.com
}

Keywords: Construction, technology, Wuhan

\begin{abstract}
As China has entered a period of a New Normal and China's "New-type urbanization" soars up, development of city construction technology thus becomes urgent. This paper analyzes the SWOT factors of construction technology development of several representative cities in recent years, and adopts AHP-SWOT analysis method to analyze the strategy of construction technology development. Since the development of construction technology has been so rapid in Wuhan in recent years, Wuhan is chosed as the sample for the research. The results turns out that the biggest strength, weakness, opportunity and threat of the construction technology development in Wuhan are respectively the solid foundation of construction technology, weak urban infrastructure, the intertsection of national strategy, the challenge brought about by the rise of other central city in middle parts of China. According to the influence of various factors on the construction science and technology development of wuhan city, we put forward specific policies to provide reference and suggestions for the city construction technology strategy in Wuhan in the end of this paper.
\end{abstract}

\section{Introduction}

China's economy has entered a period of a new normal in 2015, the economic growth will increasingly depend on productivity and innovation-driven. "National Plan on New Urbanization (2014- 2020)" requires that in promoting China's urbanization we should solve the problems of extensive low efficiency of construction land and the unreasonability of urban spatial distribution and size structure and so on [1]. Construction of new-type urbanization and economic new normal made further significant requirements of construction technology development. Construction technology development Strategy is a kind of science and technology strategy, in spite of Shenzhen, Dalian, Wuhan, Qingdao, Beijing and other cities have conducted studies on the construction of science and technology development strategy, but studies of domestic cities are still relatively small, mainly focus on science and technology development strategy.

Wuhan is the central city of China, an important node city in the "One Belt and One Road" strategy and strategic pivot in the central part of China. In view of the need and importance Wuhan municipal government to build national strategic development of science and technology development, the urgent need to speed up the construction of Wuhan Science and Technology Strategy Development. In this study, AHP-SWOT analysis, Wuhan City as an example of the construction of science and technology development strategy analysis, to provide reference for the construction of Wuhan Science and Technology Innovation Strategy.

\section{Research methods}

AHP-SWOT model. SWOT analysis was first used in the early 1980s, proposed by Professor Wei Like University of San Francisco, to grasp the basic internal strengths and weaknesses and external opportunities and threats based on the development strategy in line with the company's future development [2]. After the 1990s, SWOT analysis gradually applied to other disciplines and fields, is a qualitative methodology for technical methodological guidance [3, 4]. AHP is a decision analysis method for qualitative and quantitative analysis of operational research in the late 1970s the United States proposed a combination of home Saaty [5]. The mixed use AHP and SWOT analysis is often 
used to improve the viability SWOT analysis, because of the importance of AHP can be quantitatively determined in the SWOT factor group [6]. Many scholars at home and abroad have been taken AHP-SWOT analysis in different fields. Kurttila, Shrestha and other scholars will AHP-SWOT analysis in strategic decision-making in forestry [7,8]. The impact of construction technology development strengths factors factors weaknesses opportunities and threats factors summarize, the AHP tool to compare any two factors determine the priority of each factor. According to the role of each factor on the construction technology development system, summarizes the different development programs and propose countermeasures. In this paper SWOT factor analysis, factor analysis weights, under the theory of strategic path generation, AHP-SWOT analysis model which built construction technology development in this paper shown in Figure 1.

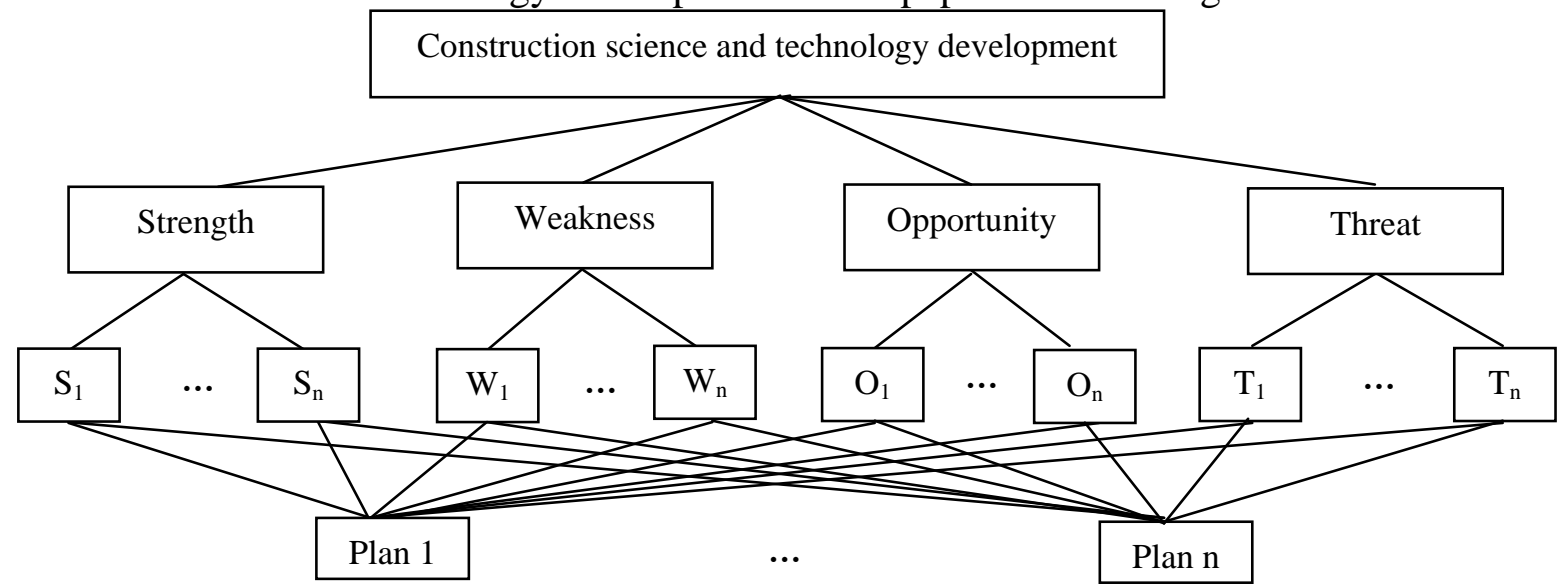

Fig. 1 AHP-SWOT analysis model of construction technology development

SWOT factors. Experts have been selected from two channels to set up experts group ,the one channel is choose one in the building industry, there are a wealth of experience and understanding of the development needs of the construction industry, the current status of the development and construction of technology people as panelists. Second, select the scholars in the construction field research. According to international practice to invite experts to between 10-25 people, based on the SWOT analysis, selected for the most important decision-making factor in building local technological development. Each of these factors into SWOT categories: strengths, weaknesses, opportunities and threats.

Judgment matrix. Judgment matrix is a matrix showing the relative importance of each hierarchy between two factors. General judgment matrix layer by layer from the target layer, layers and elements of the model based on the relationship between representation, constructed from a lower layer adjacent judgment matrix related factors, such as Formula 1. In this matrix, the feature vector

is $\mathrm{C}=\left[\mathrm{C}_{1}, \mathrm{C}_{2}, \ldots \ldots, \mathrm{C}_{\mathrm{n}}\right] \mathrm{T}$, so $\mathrm{a}_{\mathrm{ij}}=\mathrm{c}_{\mathrm{i}} / \mathrm{c}_{\mathrm{j}}, \mathrm{i}, \mathrm{j}=1,2, \cdots \cdots \mathrm{n}$, aji $=1 /$ aij; when $\mathrm{i}=\mathrm{j}$, aij $=1$; the variation range of the value of $a_{\mathrm{ij}}$ is $1 \sim 9$, the meaning of $1 / 1$ is two elements have the same importance, 9/1 indicates absolute or extremely importantance of the previous factor .

$$
\mathrm{A}=\left\{a_{i j}\right\}=\left[\begin{array}{ccc}
c_{1} / c_{1} & \cdots & c_{1} / c_{n} \\
\vdots & \ddots & \vdots \\
c_{n} / c_{1} & \cdots & c_{n} / c_{n}
\end{array}\right]
$$

According SWOT matrix factors, the advantages of group structure, group weaknesses, opportunities group and judgment matrix threat groups, SWOT feature weights to make more scientific, objective and comprehensive, we use the Delphi method, experts in the field of science invite pairwise factor comparison of scoring, the importance of the assignment in accordance with $1-9$.

Consistency Ratio(CR) and rank. Since the expert scoring with a difference, it should determine the consistency of decisions $\mathrm{CI}=\left(\lambda_{\max }-\mathrm{n}\right) /(\mathrm{n}-1), \lambda_{\max }$ is the biggest feature of the root, the value of RI in Table 1, the judgment matrix of random consistency ratio CR = CI / RI, when less than $10 \%$ CR, judgment matrix is considered to have a satisfactory consistency, which scored relatively 
experts agreement. The method using characteristic values for each set of factors to calculate the priority groups of priority where the maximum number of factors SWOT group representatives, to form a new matrix, and then sort between groups.

Table 1 RI value table

\begin{tabular}{|c|c|c|c|c|c|c|c|c|c|}
\hline $\mathrm{n}$ & 1 & 2 & 3 & 4 & 5 & 6 & 7 & 8 & 9 \\
\hline $\mathrm{RI}$ & 0 & 0 & 0.58 & 0.90 & 1.12 & 1.24 & 1.32 & 1.41 & 1.45 \\
\hline
\end{tabular}

\section{AHP-SWOT method applying in the development of construction science and technology}

SWOT factors matrix of construction science and technology development. Currently only there are Wuhan, Shenzhen, Dalian, Beijing, Chongqing and other cities to build science and technology development strategy research, we analysis the construction scientific and technological development data of the five cities in recent years, summarize the impact these five urban construction SWOT factors such as technological development table 2.

Table 2 SWOT factors matrix

\begin{tabular}{|c|c|}
\hline SWOT groups & swOT factors \\
\hline $\begin{array}{l}\text { Interal factors } \\
\text { (strenghths and } \\
\text { weaknesses) }\end{array}$ & $\begin{array}{r}\text { Foundation of construction technology development } \\
\text { Technological innovation supporting } \\
\text { development needs of urban construction } \\
\text { Research funding } \\
\text { Government support }\end{array}$ \\
\hline Exteral factors & Regional expansion and monopoly \\
(opportunities and & Regional economic development \\
threats) & Competition in the global market \\
& Human resources competition \\
& National policy and strategy \\
\hline
\end{tabular}

Based on the above factors, the selection of the city's construction technology for research. Studies have shown that the construction of Wuhan Science and Technology is developing rapidly in recent years, the Wuhan municipal government to build support for technological development and financial investment to be large compared to other cities, and affected Wuhan location factors and national policy strategy, Wuhan Construction Technology there is considerable room for development, so the development of scientific and technological development for the local level of construction in Wuhan Wuhan construction planning and Technology Development plays a crucial role.

Application basis of AHP-SWOT. The main reason for building applications AHP-SWOT Analysis Research and Technology Development Strategy are: a wide range of industries involved in the construction of science and technology development, a number of factors, both internal factors characterizing the technological development of various construction areas. Through an objective analysis of factors affecting the construction of technological development, the construction of science and technology development to understand the strengths and weaknesses and the opportunities and threats faced by the construction of science and technology to achieve the best combination of the development of the external environment and internal conditions for the development to take advantage of opportunities and avoid threats, play advantages, disadvantages overcome construction technology development strategy to provide a theoretical basis. Masozera, Kahraman and other scholars will AHP and SWOT analysis of mixed use will use case study method to check whether the applicable under certain circumstances $[9,10]$. The following will be in Wuhan, for example, the use of AHP-SWOT analysis of the construction of Wuhan science and technology development research. 


\section{Case analysis}

SWOT factors matrix. Wuhan Yangtze River economic belt at the core node and the Silk Road economic belt intersection, but also as a pilot national innovation-oriented city and the "1 + 8" City Circle building, at the same time as the rise of the central strategic fulcrum, a very large geographical advantages . Engineering design is the dominant industries in Wuhan, China Liu Cheng has built high-speed railway, the bridge on the Yangtze River Seventy-third of the key projects is "Wuhan Design", which provide good science and technology innovation support for the development of Wuhan construction science and technology. However, the central city of Wuhan, compared with developed countries, the urbanization rate is low, weak infrastructure. Expansion by both domestic and foreign core construction business monopoly threat, the threat of human resources competition, only $72 \mathrm{~km}$ length of rail transit network is currently in Wuhan, ranked ninth. In recent years, construction of the Composite Wuhan Science and Technology Development, summed up the construction of Wuhan Science and Technology Development SWOT factor matrix as shown in Table 3.

Table 3 SWOT factors matrix in Wuhan construction technology development

\begin{tabular}{|c|c|}
\hline SWOT groups & SWOT factors \\
\hline Strenghth (S) & $\begin{array}{l}\text { S1: The solid foundation of construction technology } \\
\text { S2: Regional geographical advantage is obvious } \\
\text { S3: Science and education talent resources are rich }\end{array}$ \\
\hline Weakness (W) & $\begin{array}{l}\text { W1: The urbanization level is not high, unbalanced development } \\
\text { between urban and rural areas } \\
\text { W2: The weak urban infrastructure and the construction is difficult } \\
\text { W3: The contribution rate of science and technology construction } \\
\text { progress is low, ability is not strong }\end{array}$ \\
\hline Opportunity (O) & $\begin{array}{l}\text { O1: The intersection of National strategy } \\
\text { O2: National innovative city and East lake national independent } \\
\text { innovation demonstration area construction } \\
\text { O3: Two type society construction of Wuhan" } 1+8 \text { " City Circle }\end{array}$ \\
\hline Threat (T) & $\begin{array}{l}\text { T1: The challenges of the rise of central China center for urban belt } \\
\text { T2: Strategic competitive national economic sectors } \\
\text { T3: The expansion and monopoly of core enterprise in Urban } \\
\text { internationalization in the field of scince and technology construction }\end{array}$ \\
\hline
\end{tabular}

AHP quantitative analysis of Wuhan construction science and technology development. We use the Delphi method,and have invited 20 experts in the field of construction of to mark the influence factors of the construction science and technology development two by two, Among them, there are ten managers and management personnels in Wuhan city construction business unit, and ten university scholars in the construction field of science and technology development research. According to the result of expert scoring, comparison matrix of two factors comparison within each group has been established, the priority of each factors has been calculated by utilizing the method of characteristic value, the SWOT group which has the biggest factors has been chosen, and test the consistency of comparison matrix, the factors within the priority weighting and consistency ratio CR are shown in Table 4.

According to the results in table 3, the new comparison matrix between groups has been got by the group which has the biggest priority weighting factors, which is the comparison matrix between groups composed of S1, W2, O1, T1, as shown in table 5. 
Table 4 Priority weighting factors within each group

\begin{tabular}{|c|c|c|c|c|}
\hline Group & $\begin{array}{c}\text { Influencing } \\
\text { factor }\end{array}$ & $\mathrm{RI}(\mathrm{n})$ & CR & $\begin{array}{c}\text { Priority weighting factors } \\
\text { between groups }\end{array}$ \\
\hline \multirow{3}{*}{ S } & $\mathrm{S} 1$ & \multirow{3}{*}{$0.58(3)$} & \multirow{3}{*}{0.0086} & 0.37 \\
\hline & S2 & & & 0.28 \\
\hline & S3 & & & 0.35 \\
\hline \multirow{3}{*}{ W } & W1 & \multirow{3}{*}{$0.58(3)$} & \multirow{3}{*}{0.0948} & 0.10 \\
\hline & W2 & & & 0.50 \\
\hline & W3 & & & 2.28 \\
\hline \multirow{3}{*}{$\mathrm{O}$} & $\mathrm{O} 1$ & \multirow{3}{*}{$0.58(3)$} & \multirow{3}{*}{0.0086} & 0.55 \\
\hline & $\mathrm{O} 2$ & & & 0.20 \\
\hline & $\mathrm{O} 3$ & & & 0.25 \\
\hline \multirow{3}{*}{$\mathrm{T}$} & $\mathrm{T} 1$ & \multirow{3}{*}{$0.58(3)$} & \multirow{3}{*}{0.0775} & 0.68 \\
\hline & $\mathrm{T} 2$ & & & 0.19 \\
\hline & T3 & & & 0.13 \\
\hline
\end{tabular}

Table 5 Comparison matrices between groups

\begin{tabular}{|c|c|c|c|c|}
\hline $\begin{array}{c}\text { Groups } \\
\text { elements }\end{array}$ & $\mathrm{S}_{1}$ & $\mathrm{~W}_{2}$ & $\mathrm{O}_{1}$ & $\mathrm{~T}_{1}$ \\
\hline $\mathrm{S}_{1}$ & 1 & $1 / 1.1$ & $1 / 7$ & $1 / 9$ \\
\hline $\mathrm{W}_{2}$ & 1.1 & 1 & $1 / 8$ & $1 / 3$ \\
\hline $\mathrm{O}_{1}$ & 7 & 8 & 1 & 3 \\
\hline $\mathrm{T}_{1}$ & 9 & 3 & $1 / 3$ & 1 \\
\hline
\end{tabular}

Obtained by calculation that $\mathrm{CR}=0.069<0.1$, we can judge that matrix pass the consistency check. Finally we can conclude priority weighting and sorting between groups are shown in Table 6 .

Table 6 Priority and sorting table between groups

\begin{tabular}{|c|c|c|c|c|}
\hline SWOT & S & W & O & T \\
\hline $\begin{array}{c}\text { Priority } \\
\text { weighting } \\
\text { between } \\
\text { groups }\end{array}$ & 0.06 & 0.07 & 0.58 & 0.29 \\
\hline Rank & 4 & 3 & 1 & 2 \\
\hline
\end{tabular}

Result analysis. Sort the results according to factors within SWOT factors between group A and group shows, Wuhan Science and Technology Development building opportunities facing> threat> Disadvantages $>$ advantages, the biggest advantage of the construction of Wuhan Science and Technology Development, weaknesses, opportunities and threats for the construction of science and technology base, city weak infrastructure challenges of national strategic meeting point to bring the central city of central China. Advantages of minimal impact reason may be that construction science and technology development in Wuhan city fails to make full use of its own construction and talent advantages, and the weakness of urban infrastructure is more prominent compared advantage currently in Wuhan. Wuhan City should take advantage of the national strategy to develop the intersection of promoting the construction of Wuhan Science and Technology, and seize "along the way", "Rise of Central China", "renaissance big Wuhan" development opportunity, accelerate the development of urban construction and building technology, explore the future of urbanization development in Wuhan. While strengthening the construction of scientific and technological base strong scientific and technological advantages and personnel, strengthen the local construction business restructuring and research capacity, enhance domestic and foreign construction enterprises core competitive strength. 


\section{Conclusions}

This case study was the first in the area of construction science and technology, AHP-SWOT as a combination method of a qualitative and quantitative analysis of strategic decision-making, making the decision analysis become objective in some extent. In this paper, AHP-SWOT analysis method analyzed the development of construction science and technology advantages, weaknesses, opportunities and threats in Wuhan, Strategic decisions for the future construction of Wuhan Science and Technology for Sustainable Development provides a reference, while also providing research strategic decision to build a science and technology development in other cities of methods to ensure its construction science and technology development strategy choices are quantitative basis.

\section{References}

[1] The State Council of the people's Republic of China. [2014] ninth, "new urbanization plan for the state (2014 2020)"[ EB/OL], (2014-03-30)[2015-05-13].

http://www.gov.cn/zhengce/2014-03/16/content_2640075.htm

[2] Zhang Qinyuan, The application of SWOT analysis in the strategic management. Enterprise reform and management, No. 02, (2006).

[3]Gong Xiaojun, SWOT analysis as strategic research general analysis methods. Journal of Xi'an Electronic and Science University (SOCIAL SCIENCE EDITION), No. 01 (2003).

[4] Yuan Mu, Zhang Xiaoguang, YangMing. SWOT Analysis in Urban Strategic Planning: Application and Innovation. City Planning Review, No. 04, (2007).

[5] Zhao Kun, Hong Xiangdong. Application of AHP in Strategic Alignment Model. Journal of Yunnan University of Finance and Economics, No. 01, (2003).

[6] Lee S, Walsh P. SWOT and AHP hybrid model for sport marketing outsourcing using a case of intercollegiate sport[J]. Sport Management Review, Vol. 14, No. 4, (2011): 361-369.

[7] Kurttila M, Pesonen M, Kangas J, et al. Utilizing the analytic hierarchy process (AHP) in SWOT analysis - a hybrid method and its application to a forest-certification case. Forest Policy \& Economics, Vol. 1, No.1, (2000), p.41-52.

[8] Shrestha R K, Alavalapati J R R, Kalmbacher R S. Exploring the potential for silvopasture adoption in south-central Florida: an application of SWOT-AHP method. Agricultural Systems, Vol. 81, No.3, (2004) ,p.185-199.

[9] Kahraman C, Demirel N , Demirel T. Prioritization of e-Government strategies using a SWOT-AHP analysis: the case of Turkey[J]. European Journal of Information Systems, , volume Vol. 16, No.3 (2007), p.284-298(15).

[10] Masozera M K, Alavalapati J R R, Jacobson S K, et al. Assessing the suitability of community-based management for the Nyungwe Forest Reserve, Rwanda[J]. Forest Policy \& Economics, Vol. 8. No.2, (2006), p.206-216. 